\title{
Cross-cultural adaptation of the primary health care satisfaction questionnaire
}

Adaptação transcultural do questionário de satisfação com os cuidados primários de saúde

\author{
Elisabete Pimenta Araujo Paz ${ }^{1}$ \\ Pedro Miguel Santos Dinis Parreira ${ }^{2}$ \\ Alexandrina de Jesus Serra Lobo ${ }^{3}$ \\ Rosilene Rocha Palasson ${ }^{1}$ \\ Sheila Nascimento Pereira de Farias ${ }^{1}$
}

Keywords

Nursing research; Primary care nursing;

Public health nursing; Validation studies; Consumer satisfaction; Primary

health care

\section{Descritores}

Pesquisa em enfermagem; Enfermagem de atenção primária; Enfermagem em saúde pública; Estudos de validação; Satisfação do usuário; Atenção primária à saúde

Submitted March 12, 2014

Accepted July 29, 2014
Corresponding author

Elisabete Pimenta Araujo Paz

Afonso Cavalcanti street, 275,

Rio de Janeiro, RJ, Brazil.

Zip Code: 2011-110

bete.paz@gmail.com

DOI

http://dx.doi.org/10.1590/1982-

0194201400070

\begin{abstract}
Objective: To develop the cross-cultural validation and assessment of the psychometric properties of the Questionnaire about the quality and satisfaction dimensions of patients with primary health care.

Methods: Methodological cultural adaptation and assessment study of the psychometric properties, involving 398 users from a primary care service. The construct validity was verified through principal components factor analysis and internal consistency assessment as determined by Cronbach's alpha, using SPSS.

Results: A factorial structure was identified that is equivalent to the original instrument, showing six factors that explain $70.81 \%$ of the total variance. All internal consistency coefficients were higher than 0.84 , indicating appropriate psychometric properties.

Conclusion: The results show that the Brazilian Portuguese version of the instrument is culturally and linguistically appropriate to assess the satisfaction of users attended in primary care services.

\section{Resumo}

Objetivo: Realizar a validação transcultural e avaliação das propriedades psicométricas do Questionário sobre as dimensões de qualidade e satisfação de pacientes com cuidados primários de saúde.

Métodos: Estudo metodológico de adaptação cultural e avaliação das propriedades psicométricas com participação de 398 usuários de uma unidade de atenção primária. A validade de construto foi verificada através da análise fatorial em componentes principais e avaliação da consistência interna determinada pelo Alfa de Cronbach com uso do SPSS.

Resultados: Identificou-se estrutura fatorial equivalente ao instrumento original emergindo seis fatores que explicam $70,81 \%$ da variância total. Todos os valores de consistência interna foram superiores a 0,84 denotando propriedades psicométricas adequadas.

Conclusão: Os resultados evidenciam uma adequação cultural e linguística do instrumento na versão em português do Brasil, mostrando-se adequado para avaliar a satisfação dos usuários atendidos em unidades primárias de saúde.
\end{abstract}

'Escola de Enfermagem Anna Nery, Universidade Federal do Rio de Janeiro, Rio de Janeiro, RJ, Brazil.

${ }^{2}$ Escola Superior de Enfermagem de Coimbra, Coimbra, Portugal.

${ }^{3}$ Escola Superior de Enfermagem Dr. José Timóteo Montalvão Machado, Chaves, Portugal.

Conflicts of interest: no conflicts of interest to declare. 


\section{Introduction}

Primary care is the first level of care supply for a good performance of health systems, and offers care to people and their most common problems. Studies demonstrate better health and user satisfaction indicators, besides lower health costs in countries whose health systems are guided by primary health care. $^{(1,2)}$

User satisfaction is considered one of the main objectives of health services, playing an increasingly relevant role in the assessment and guarantee of health service quality in order to offer, in the health system, the care that is necessary, accessible and appropriate to the expectations of the population that directly uses the public health service. ${ }^{(2-4)}$

Different factors influence the satisfaction with the health service, such as the local culture, the knowledge about how the service functions, the professionals' attitudes towards the users' demands, the trust in the health professional, past experiences in using the service, compliance with one's needs, treatment success, among others. Given the subjective and multidimensional nature of satisfaction, this concept is difficult to operate in function of expectations and demands the services respond to, which involve the technical and interpersonal aspects of care. The more satisfied the users are with the health service, the more receptive they can be to the professional orientations to improve their health and choose that service as their reference for treatment. ${ }^{(4,5)}$

The instruments used to assess satisfaction with health services are often insufficient to dimension what they really want to measure, mainly if the object that is being measures has subjective characteristics. Reaching a consensus in this area remains difficult. ${ }^{(6,7)}$ Therefore, the particularities of the service and clients being assessed should always be considered, mainly if instruments from other countries and social realities are used, which require adaptation to another sociocultural reality. The cross-cultural validation of instruments permits guaranteeing the validity and reliability of the adapted instruments, assessing what one intends to discover in another context, culture and age, and permits the comparison of results with other populations. ${ }^{(8,9)}$

This study was aimed at developing the cross-cultural validation for Brazil of the Portuguese version of the Questionnaire about the quality and satisfaction dimensions of patients with primary health care, elaborated by Raposo, Alves and Duarte. ${ }^{(10)}$

\section{Methods}

Methodological cultural adaptation and assessment study of the psychometric properties of the Portuguese version of the Questionnaire about the quality and satisfaction dimensions of patients with primary health care, elaborated by Raposo, Alves and Duarte. ${ }^{(10)}$ The original version consists of 33 items, organized in five dimensions: health service facilities, administrative attendance, nursing service, medical care and care in general, with statements in the form of a seven-point Likert scale, ranging from 1-I completely disagree; 2-I strongly disagree; 3-I somewhat disagree; 4-I neither agree nor disagree; 5-I somewhat agree; 6-I strongly agree; to 7-I completely agree.

The study was undertaken at a Family Clinic in planning area 3.1 of the city of Rio de Janeiro, in the Brazilian Southeast, located in a region that has recently gone through a pacification process, involving the continuing presence of the military police to eradicate the social conflicts that were common.

\section{Cross-cultural adaptation}

Initially, the authors of the questionnaire were asked for and granted their authorization for the development of the validation process and further use with the Brazilian population. To undertake the cross-cultural adaptation process, the guidelines proposed in international $^{(9,11)}$ and Brazilian ${ }^{(12)}$ studies were followed, which include five phases: translation, first consensus version, back-translation, expert committee and pre-test. 


\section{Phase I and Phase II}

In the first phase, two independent translations were elaborated (T1 and T2 of the instrument from the original language (source language) to Brazilian Portuguese) by one of the nurse researchers and a physician, both of whom worked in Primary Health Care, when possible difficulties were verified to understand words that could be semantically adapted to our context. In addition, the translators were asked to assess the difficulty of each scale item and, therefore, a score from zero (very difficult) to ten (very easy) was elaborated. Words that were biased or whose meaning was unclear were marked in the questionnaire, together with proposals for improvement in the Brazilian version, as these words were not current in Brazil.

Based on the independent translations, a sociologist fluent in Portuguese from Portugal developed a back-translation, which considered the original questionnaire, the items that maintained the semantic equivalence of the questions (same meaning), the conceptual equivalence (same concepts in both cultures) and the simple and direct formulation of the questions. Small changes were made, in line with the study objectives, and incorporated into the translators' suggestions, which resulted in the consensus version.

\section{Phases III and IV}

A panel of specialists (expert committee) compared the original version in Portuguese, the consensus translation to Brazilian Portuguese and the back-translation to Portuguese from Portugal, including a Brazilian epidemiologist, a Brazilian nurse researcher who works with the family health strategy, a Portuguese nursing teacher with a Ph.D. who worked in service management and a Portuguese nursing teacher who researched on health service quality and had experience in the use of the original questionnaire. All questions from the consensus version were analyzed to assess the extent to which the content of each item reflected the meaning and content of the original version. The decisions made followed the proposals by Guillemin, ${ }^{(11)}$ aiming for equivalence between the original version and the Brazilian version, considering four areas: semantic equivalence, idiomatic equivalence, experiential equivalence and conceptual equivalence.

The words or expressions with different meanings were removed or adjusted to reflect in the translated version the same content as the original version, leading to the validity of the instrument. Coarse inconsistencies and/or conceptual translation errors were eliminated and the consensus was followed, which resulted in a version with a $100 \%$ agreement level. Then, any discrepancies were assessed, homogenizing the formulation based on the consensus. Examples are the original sentences "By standard the waiting time to be treated in short", changed to "The nurses/physicians respect the service hours"; "The attendance cabinets offer sufficient space", changed to "The consultation rooms offer sufficient space".

\section{Phases V and VI}

The consensus version was applied to 20 users from a family health clinic that was not included in the study, as the final phase of the cultural adaptation process. In the pre-test phase, no difficulties were observed to understand and interpret the questions. Therefore, the researchers found the re-test unnecessary, immediately moving on to the application of the consensus version.

\section{Field Research}

The questionnaire was applied by means of an interview to 398 users who complied with the inclusion criteria and attended the Family Health Clinic with health demands. The interviews took place in the morning and afternoon shifts, from Mondays to Fridays, between August $5^{\text {th }}$ and November 28th 2013, before medical or nursing care, or while the user was waiting for some procedure at the clinic. The average duration of the interviews was 15 minutes and the interviewers were grantees, who received training for this procedure.

At the start of the data collection, the study objectives and interview procedures were briefly presented and the participants' confidentiality and anonymity were guaranteed. Then, the Free and Informed Consent Term was read, a compulsory document in research involving human beings, which 
contained detailed information about the research phases, methods, possible risks for the participants and conducts to avoid them. The understanding of its content and the signature guarantee the participants' autonomy, in compliance with the ethical principles of research.

The data were organized in a database and the statistical analyses were developed in the software Statistical Package for the Social Sciences version 20.0, including descriptive and trend analyses. To analyze the internal consistency, that is, the extent to which all items measure the same construct of the scale, Cronbach's Alpha was used.

The development of this study complied with the Brazilian and international ethical standards for research involving human beings.

\section{Results}

\section{Characteristics of respondents}

The sample consisted of $74.1 \%$ female and $25.9 \%$ male respondents. The mean age was 41 years, with a standard deviation of 15.72 years, ranging between 18 and 84 years. As regards the self-referred skin color/race, $48.6 \%$ are mulatto, $28 \%$ black, $21.2 \%$ white and $1.5 \%$ indigenous. 9.3\% live alone. Among the interviewees, 36.7\% had finished the second cycle of secondary education $\left(5^{\text {th }}\right.$ to $9^{\text {th }}$ grade) and $24.6 \%$ the first cycle of secondary education ( $1^{\text {st }}$ to $4^{\text {th }}$ grade). In the interviewed sample, $55.8 \%$ did not inform any formal job.

In terms of monthly income in minimum wages, $38.4 \%$ receive between 1 and 2 wages, 32.4\% gained no income and $11.8 \%$ informed gaining some kind of financial aid from the government. Concerning how frequently they tend to visit the health service, $35.5 \%$ informed 2 to 6 times per year, $25.6 \%$ once per month and $12.7 \%$ weekly, with $59.7 \%$ informing routine consultation as the reason to visit the service.

As regards the satisfaction with the location of the service, $93.7 \%$ are satisfied or highly satisfied, but $5.3 \%$ of the users experience difficulties to reach the health service, $72.9 \%$ take up to 15 minutes to reach the service and $94.2 \%$ do not spend anything on transportation.

Only $17.1 \%$ of the users are able to schedule an appointment on the same day, 29.2\% take between 2 and 4 weeks to get a medical appointment and $28.4 \%$ between 1 and 2 months. As regards the delay in the waiting room to consult the physician, $58.8 \%$ are attended within the first hour and $15.2 \%$ wait more than 2 hours for this consultation.

Concerning the delay to get a nursing consultation, $35.9 \%$ of the users manage this on the same day. Although $74.9 \%$ got the nursing consultation within 30 days, $25.1 \%$ informed waiting between 1 and 6 months. 42.4\% informed waiting up to 30 minutes at the waiting room for the nursing consultation.

In the analysis of the user satisfaction scale, first, the scale items were assessed according to the dispersion of the answers, showing that the users' assessment were distributed across all agreement levels, indicating an appropriate discriminatory power of the items (Table 1). The scores tend to be much higher than the midpoint of the scale, indicating the users' global satisfaction.

The questions with the lowest mean scores are related to the mean waiting time to get medical and nursing care. In addition, the mean score of 4.85 is observed for the question "This health service borders closely on a perfect health service", indicating that, although the users feel satisfied, they acknowledge that the service does not fully attend to their expectations.

\section{Construct validity}

The construct validity of a concept like satisfaction, which is constantly changing and evolving, besides its subjectivity, although complex, shows to be decisive in order to be considered a measure of credibility. The dimensionality of the instrument was assessed by means of principal components factor analysis (PCA), followed by the internal consistency assessment using Cronbach's Alpha and the item-factor correlations. In the interpretation of the factor, a minimum factor loading of \pm 0.30 was set for the PCA. The number of factors with an eigen- 
Table 1. Minimum, maximum, mean and standard deviation of the items in the primary health care user satisfaction questionnaire $\mathrm{N}=398$

\begin{tabular}{|c|c|c|c|c|c|}
\hline Item & Variables of Satisfaction Scale & Minimum & Maximum & Mean & Standard Deviation \\
\hline 1 & Facilities look good & 1 & 7 & 6.25 & 1.06 \\
\hline 2 & Temperature in the facilities is pleasant & 1 & 7 & 6.06 & 1.31 \\
\hline 3 & Facilities are comfortable & 1 & 7 & 6.13 & 1.12 \\
\hline 4 & Facilities are clean & 1 & 7 & 6.30 & 1.02 \\
\hline 5 & Bathrooms are in good hygienic conditions & 1 & 7 & 5.99 & 1.23 \\
\hline 6 & There is sufficient space in the consultation rooms & 1 & 7 & 6.21 & 1.16 \\
\hline 7 & The facilities at the clinic are appropriate for disabled people & 1 & 7 & 5.63 & 1.59 \\
\hline 8 & The services are well signaled & 1 & 7 & 5.99 & 1.37 \\
\hline 9 & The functioning hours are appropriate to your needs & 1 & 7 & 5.70 & 1.66 \\
\hline 10 & At this clinic, there is information about health care & 1 & 7 & 5.72 & 1.67 \\
\hline 11 & The Community Agents are thoughtful & 1 & 7 & 6.05 & 1.39 \\
\hline 12 & The Community Agents take interest in your problems and their solution & 1 & 7 & 5.85 & 1.52 \\
\hline 13 & The Community Agents clearly explain what you have to do & 1 & 7 & 5.94 & 1.51 \\
\hline 14 & One normally waits little to be attended & 1 & 7 & 5.11 & 1.80 \\
\hline 15 & The nurses are thoughtful & 1 & 7 & 6.11 & 1.24 \\
\hline 16 & The nurses take interest in your problems and their solution & 1 & 7 & 5.94 & 1.35 \\
\hline 17 & The nurses do everything they can to solve your problem & 1 & 7 & 5.87 & 1.49 \\
\hline 18 & The nurses clearly explain the treatment you will have to do & 1 & 7 & 5.97 & 1.43 \\
\hline 19 & The nurses are competent in the treatments they give you & 1 & 7 & 6.01 & 1.42 \\
\hline 20 & Normally the nurse is available to treat you & 1 & 7 & 5.60 & 1.62 \\
\hline 21 & The nurses respect the functioning hours & 1 & 7 & 5.20 & 1.73 \\
\hline 22 & Normally, one waits little to be attended & 1 & 7 & 4.61 & 1.87 \\
\hline 23 & The physicians are thoughtful & 1 & 7 & 6.40 & 1.15 \\
\hline 24 & The physicians take interest in your problems and their solution & 1 & 7 & 6.36 & 1.15 \\
\hline 25 & The physicians clearly explain the treatments you will have to get & 1 & 7 & 6.41 & 1.12 \\
\hline 26 & The physicians do everything they can to solve your problem & 1 & 7 & 6.26 & 1.26 \\
\hline 27 & The physicians are competent in the treatments they give you & 1 & 7 & 6.29 & 1.27 \\
\hline 28 & The physicians respect the functioning hours & 1 & 7 & 5.48 & 1.79 \\
\hline 29 & One normally waits little to be attended & 1 & 7 & 4.76 & 1.88 \\
\hline 30 & In general, you feel satisfied with the service at this health unit & 1 & 7 & 5.70 & 1.55 \\
\hline 31 & This health unit corresponds to your needs & 1 & 7 & 5.70 & 1.52 \\
\hline 32 & This health service attends to your expectations & 1 & 7 & 5.38 & 1.68 \\
\hline 33 & This health service is very close to a perfect health service & 1 & 7 & 4.85 & 1.85 \\
\hline
\end{tabular}

value superior to one and Cattell's Scree test determined the number of factors for extraction.

The principal components factor analysis resulted in six factors. The matrix produced evidenced a Kaiser Meyer-Olkin (KMO) coefficient of .919 with significance for Bartlett's test of sphericity (BTS) $\left(\mathrm{c}^{2}=11171.324, \mathrm{p}=.000\right)$, indicating the appropriateness of the sample and the correlation matrix for the factoring. The analysis revealed six factors with an eigenvalue superior to 1 , which explain $70.82 \%$ of the variance, respectively $20.31 \%$ for the first factor, $12.72 \%$ for the second factor, $12.57 \%$ for the third factor, $10.58 \%$ for the fourth factor, $9.43 \%$ for the fifth factor and $5.20 \%$ for the sixth factor. Some small changes in relation to the original scale were observed, which nevertheless did not undermine any of the factors.
Concerning the characteristics of the original and adapted factors (Table 2), these were organized in F1-Nursing Care; F2-Medical Care; F3Health Service Facilities; F4-Global Satisfaction; F5-Administrative Attendance; F6-Medical Care: Time and waiting time. The mean and standard deviation for each of the factors were, respectively: F1- 1.26 and 5.69; F2- 6.35 and 1.06; F3- 6.04 and 086; F4- 1.37 and 5.48; F5-5.73 and 1.34; F6-1.70 and 5.12.

The factor "Medical Care" in the original scale was divided in two factors, the first was called "F2Medical Care", which groups aspects like the interest in the problems and their solution, the explanation of the treatment needed, the attention and competency of the professional to solve the problems the user presented during the consultation. The second factor, called "F6- Medical Care: Time 
and waiting time", refers to aspects related to the waiting time and the physicians' compliance with the time of the appointment. A slight factorial bias is observed, with scores bordering on 0.30 for the question "At this clinic there is information about health care". It shows a higher saturation level in F4 - "Global Satisfaction" than in F3- "Health Service Facilities" though, grouping questions about the users' expectation and satisfaction.

\section{Reliability}

The trust in the permanence of the results across several applications of a certain scale or test, always associated with an error that needs to be reduced, is called reliability. For this purpose, the internal consistency method is adopted, obtained through the mean correlation between all items and the final test score or factor in question, considering the component items. Cronbach's Alpha is the most used test when the items are non-dichotomous and serves as a good reliability estimate in most situations.

As a reference point, 0.80 is considered, although coefficients of 0.60 or higher are acceptable when the number of items is small. The results showed that all factors showed internal consistency coefficients superior to 0.88 , demonstrating that the instrument is reliable, like the original instrument.

Table 2. User satisfaction: Percentage of explained variance, factorial saturations, commonalities $\left(\mathrm{h}^{2}\right)$ and internal consistencies per factor

\begin{tabular}{|c|c|c|c|c|c|c|c|c|}
\hline \multirow[b]{2}{*}{ Item } & \multirow[b]{2}{*}{ Scale variables the level of satisfaction } & \multicolumn{7}{|c|}{ Factors, \% explained variance and commonalities } \\
\hline & & $\begin{array}{c}\text { F1 } \\
20.31 \%\end{array}$ & $\begin{array}{c}\text { F2 } \\
12.72 \% \\
\end{array}$ & $\begin{array}{c}\text { F3 } \\
12.57 \% \\
\end{array}$ & $\begin{array}{c}\text { F4 } \\
10.58 \%\end{array}$ & $\begin{array}{c}\mathrm{F} 5 \\
9.43 \% \\
\end{array}$ & $\begin{array}{c}\text { F6 } \\
5.20 \% \\
\end{array}$ & $h^{2}$ \\
\hline 17 & The nurses do everything they can to solve your problem & 0.908 & & & & & & 0.911 \\
\hline 18 & The nurses clearly explain the treatment you will have to do & 0.900 & & & & & & 0.896 \\
\hline 19 & The nurses are competent in the treatments they give you & 0.899 & & & & & & 0.905 \\
\hline 16 & The nurses take interest in your problems and their solution & 0.891 & & & & & & 0.861 \\
\hline 15 & The nurses are thoughtful & 0.885 & & & & & & 0.860 \\
\hline 20 & Normally the nurse is available to treat you & 0.883 & & & & & & 0.858 \\
\hline 21 & The nurses respect the functioning hours & 0.847 & & & & & & 0.846 \\
\hline 22 & Normally, one waits little to be attended & 0.798 & & & & & & 0.768 \\
\hline 24 & The physicians take interest in your problems and their solution & & 0.857 & & & & & 0.858 \\
\hline 25 & The physicians clearly explain the treatments you will have to get & & 0.807 & & & & & 0.786 \\
\hline 23 & The physicians are thoughtful & & 0.799 & & & & & 0.775 \\
\hline 26 & The physicians do everything they can to solve your problem & & 0.798 & & & & & 0.801 \\
\hline 27 & The physicians are competent in the treatments they give you & & 0.774 & & & & & 0.753 \\
\hline 3 & Facilities are comfortable & & & 0.718 & & & & 0.591 \\
\hline 4 & Facilities are clean & & & 0.690 & & & & 0.536 \\
\hline 1 & Facilities look good & & & 0.658 & & & & 0.490 \\
\hline 2 & Temperature in the facilities is pleasant & & & 0.641 & & & & 0.446 \\
\hline 5 & Bathrooms are in good hygienic conditions & & & 0.618 & & & & 0.489 \\
\hline 6 & There is sufficient space in the consultation rooms & & & 0.582 & & & & 0.491 \\
\hline 7 & The facilities at the clinic are appropriate for disabled people & & & 0.578 & 0.317 & & & 0.470 \\
\hline 8 & The services are well signaled & & & 0.488 & & & & 0.367 \\
\hline 9 & The functioning hours are appropriate to your needs & & 0.306 & 0.451 & 0.307 & & & 0.411 \\
\hline 31 & This health unit corresponds to your needs & & & & 0.814 & & & 0.823 \\
\hline 32 & This health service attends to your expectations & & & & 0.782 & & & 0.824 \\
\hline 30 & In general, you feel satisfied with the service at this health unit & & & & 0.773 & & & 0.797 \\
\hline 33 & This health service is very close to a perfect health service & & & & 0.734 & & & 0.717 \\
\hline 10 & At this clinic, there is information about health care & & & $0, .15$ & 0.333 & & & 0.335 \\
\hline 12 & The Community Agents take interest in your problems and their solution & & & & & 0.879 & & 0.802 \\
\hline 11 & The Community Agents are thoughtful & & & & & 0.862 & & 0.871 \\
\hline 13 & The Community Agents clearly explain what you have to do & & & & & 0.815 & & 0.802 \\
\hline 14 & One normally waits little to be attended & & & & 0.390 & 0.604 & & 0.593 \\
\hline 29 & One normally waits little to be attended & & & & & & 0.809 & 0.821 \\
\hline 28 & The physicians respect the functioning hours & & 0.349 & & & & 0.753 & 0.815 \\
\hline \multirow{2}{*}{\multicolumn{2}{|c|}{ Cronbach's Alpha }} & $0.94^{*}$ & $0.94^{*}$ & $0.84^{*}$ & $0.91^{*}$ & $0.88^{\star}$ & $0.84^{\star}$ & \\
\hline & & $0.96^{\star}$ & $0.94^{*}$ & $0.93^{\star}$ & $0.94^{*}$ & $0.93^{\star}$ & & \\
\hline
\end{tabular}

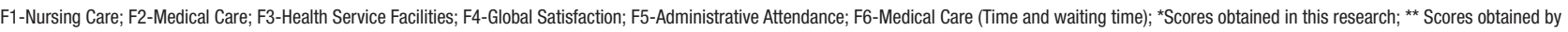
Raposo, Alves and Duarte (2009) 
In addition, coefficients superior to the midpoint of the scale are found, highlighting a higher satisfaction level in Factor 2 "Medical Care" and a lower satisfaction level in Factor 6- "Medical Care: Time and waiting time", considering the time and waiting time for medical care.

\section{Correlation study}

The validity of the items, assessed using Pearson's item/factors correlation, with and without overlapping of the item, Pearson's two-tailed r correlations between the factors and the principal components analysis are displayed in table 3.

All items show higher correlation coefficients without overlapping with the dimension they theoretically belong to than with other dimensions, sug-

Table 3. Correlações entre os itens e os fatores com e sem sobreposição

\begin{tabular}{|c|c|c|c|c|c|c|c|}
\hline Item & $\begin{array}{c}\text { Without overlapping } \\
\text { of the item }\end{array}$ & F1 & F2 & F3 & F4 & F5 & F6 \\
\hline p15 & 0.785 & 0.824 & 0.625 & 0.588 & 0.452 & 0.284 & 0.428 \\
\hline p16 & 0.823 & 0.859 & 0.635 & 0.563 & 0.514 & 0.330 & 0.434 \\
\hline p17 & 0.865 & 0.896 & 0.670 & 0.558 & 0.530 & 0.351 & 0.399 \\
\hline p18 & 0.840 & 0.875 & 0.675 & 0.543 & 0.509 & 0.365 & 0.406 \\
\hline p19 & 0.861 & 0.891 & 0.679 & 0.566 & 0.596 & 0.439 & 0.423 \\
\hline p20 & 0.815 & 0.860 & 0.572 & 0.551 & 0.586 & 0.366 & 0.468 \\
\hline p21 & 0.765 & 0.825 & 0.527 & 0.490 & 0.563 & 0.351 & 0.642 \\
\hline p22 & 0.660 & 0.747 & 0.460 & 0.480 & 0.552 & 0.387 & 0.622 \\
\hline p23 & 0.859 & 0.653 & 0.903 & 0.477 & 0.492 & 0.371 & 0.459 \\
\hline p24 & 0.890 & 0.622 & 0.925 & 0.464 & 0.494 & 0.340 & 0.471 \\
\hline p25 & 0.830 & 0.595 & 0.880 & 0.429 & 0.507 & 0.338 & 0.502 \\
\hline p26 & 0.846 & 0.623 & 0.897 & 0.424 & 0.549 & 0.396 & 0.478 \\
\hline p27 & 0.818 & 0.635 & 0.878 & 0.459 & 0.509 & 0.435 & 0.466 \\
\hline p1 & 0.528 & 0.374 & 0.308 & 0.612 & 0.292 & 0.263 & 0.226 \\
\hline p2 & 0.533 & 0.388 & 0.304 & 0.637 & 0.299 & 0.236 & 0.266 \\
\hline p3 & 0.631 & 0.415 & 0.289 & 0.705 & 0.388 & 0.230 & 0.300 \\
\hline p4 & 0.616 & 0.389 & 0.290 & 0.686 & 0.377 & 0.323 & 0.267 \\
\hline p5 & 0.625 & 0.448 & 0.340 & 0.709 & 0.386 & 0.362 & 0.320 \\
\hline p6 & 0.591 & 0.485 & 0.446 & 0.676 & 0.408 & 0.347 & 0.299 \\
\hline p7 & 0.626 & 0.483 & 0.324 & 0.733 & 0.440 & 0.343 & 0.305 \\
\hline p8 & 0.521 & 0.494 & 0.327 & 0.633 & 0.408 & 0.354 & 0.280 \\
\hline p9 & 0.523 & 0.468 & 0.435 & 0.656 & 0.475 & 0.327 & 0.340 \\
\hline P10 & 0.498 & 0.443 & 0.345 & 0.442 & 0.642 & 0.396 & 0.320 \\
\hline P30 & 0.792 & 0.604 & 0.519 & 0.494 & 0.857 & 0.557 & 0.447 \\
\hline P31 & 0.818 & 0.547 & 0.530 & 0.473 & 0.875 & 0.505 & 0.486 \\
\hline P32 & 0.855 & 0.578 & 0.535 & 0.527 & 0.905 & 0.506 & 0.582 \\
\hline P33 & 0.773 & 0.464 & 0.434 & 0.429 & 0.856 & 0.469 & 0.535 \\
\hline P11 & 0.776 & 0.313 & 0.298 & 0.360 & 0.433 & 0.852 & 0.185 \\
\hline P12 & 0.849 & 0.325 & 0.331 & 0.442 & 0.506 & 0.906 & 0.280 \\
\hline P13 & 0.817 & 0.444 & 0.472 & 0.411 & 0.515 & 0.885 & 0.317 \\
\hline P14 & 0.679 & 0.390 & 0.385 & 0.399 & 0.561 & 0.810 & 0.392 \\
\hline P28 & 0.834 & 0.547 & 0.524 & 0.382 & 0.518 & 0.297 & 0.925 \\
\hline P29 & 0.841 & 0.540 & 0.465 & 0.415 & 0.559 & 0.370 & 0.932 \\
\hline
\end{tabular}

*Coefficients obtained in this research; ** Coefficients obtained by Raposo, Alves and Duarte (2009) gesting interdependence among factors, showing that the scale represents the factors of user satisfaction and possesses sufficient familiarity to constitute distinct dimensions (discriminant convergent validity). The correlations are stronger with the factor/dimension they theoretically belong to than with others, complementing the homogeneity of the content of the items inside each factor/dimension. It is highlighted that, globally, the coefficients are superior to 0.70 , except for items $1,2,6,8,9$ and $10(0.528 ; 0.533 ; 0.591$; 0.521 and 0.523 , respectively).

\section{Discussion}

In this study, the five phases of the cross-cultural adaptation process were described that contributed to the validation for Brazilian Portuguese of the Questionnaire about the quality and patient satisfaction dimensions with primary health care. An instrument was produced that is equivalent to the Portuguese version for use in Brazil, guaranteeing its idiomatic and semantic equivalence. The assessment of the instrument's psychometric properties through the construct validity study showed that the questions addressed in the instrument measure what they were intended to measure. The internal consistency determined by Cronbach's Alpha, superior to 0.84 for all dimensions, indicated the high level of reliability of the instrument, as found in other studies that used psychometrics to measure subjective phenomena that involve behaviors and service assessment. ${ }^{(13-18)}$

For the nurses, using an instrument that assesses the satisfaction with their individual and team work contributes to gain knowledge on the impact of their activities, leading to the adaptation of actions and enhancing their social visibility in the primary care context, adopting continuous quality improvement and communication strategies with a view to care effectiveness.

Globally, the analysis of each item's correlation with the factors showed that each items is more strongly correlated with the factor it belongs to that with other factors, as a sign of validity. ${ }^{(14,15)}$ Despite showing higher mean values in all dimen- 
sions, the results show lower mean values in the dimension Medical Care: time and waiting time, which contributes to a negative assessment of the health service.

The choice to hold the interviews at the clinic to facilitate the users' participation, mainly considering the low education level of the population who uses the health service, with possible difficulties to read the questions, may have caused a bias due to the sole participation of users present at the health service, influencing the participants' response pattern, which represents a limitation in the assessment of the results.

\section{Conclusion}

The instrument Primary Health Care User Satisfaction, in the phases of the cross-cultural adaptation process of its version translated to Brazil, showed to be appropriate in psychometric terms, balanced and effective for use in primary care services, such as family health services, and demonstrates equivalence with the original version from Portugal.

\section{Collaborations}

Paz EPA; Parreira PMSD; Lobo AJS; Palasson RR and Farias SNP declare that they contributed to the conception of the project, analysis and interpretation of the data, writing of the paper, relevant critical review of the intellectual content and final approval of the version for publication.

\section{References}

1. Nascimento AP, Santos LF, Carnut L. [Primary health care via family strategy in unified health system: introduction to the problems inherent in the operation of their actions]. J Manag Prim Health Care. 2011;2 (1):18-24. Portuguese.

2. Cruz A. [Primary health care in Brazil: the challenges to enhance the gateway SUS for brazilians]. Consensus. 2008;35:4-9. Portuguese.
3. Felismina M, Mantovani MF, Gemito ML, Lopes MJ. [User satisfaction with primary health care]. Rev Enf Ref. 2013;3(9):17-25. Portuguese.

4. Brito TA, Jesus CS, Fernandes MH. [Factors associated with user satisfaction in physical therapy services]. Rev Baiana Saúde Pública. 2012; 36(2):514-26. Portuguese.

5. Rosa RB, Pelegrini AH, Lima MA. [Problem-solving capacity of assistance and users' satisfaction of the Family Health Strategy]. Rev Gaúcha Enferm. 2011;32(2):345-51. Portuguese.

6. Esperidião MA, Trad LA. [Evaluation of user satisfaction]. Cênc Saúde Coletiva. 2005;10(Suppl):303-12. Portuguese.

7. Esperidião MA, Trad LA. [Evaluation of user satisfaction assessment: Theoretical and conceptual concerns]. Cad Saúde Pública. 2006;22(6):1267-76. Portuguese.

8. Gjersing L, Caplehorn JR, Clausen T. Cross-cultural adaptation of research instruments: language, setting, time and statistical considerations. BMC Medical Res Metodol. 2010;10(1):13.

9. Beaton DE, Bombardier C; Guillemin F, Ferraz MB. Recommendations for the Cross-Cultural Adaptation of the DASH \& QuickDASH Outcome Measures. $2^{\text {th }}$ ed. Toronto: Institute for Work \& Health; 2007.

10. Raposo ML, Alves HM, Duarte PA. Dimensions of service quality and satisfaction in healthcare: a pacient's satisfaction index. Serv Bus. 2009;3:85-100.

11. Guillemin F, Bombardier C, Beaton D. Cross-cultural adaptation of health-related quality of life measures: literature review and proposed guidelines. J Clin Epidemiol. 1993;46(12):1417-32.

12. Reichenheim ME, Moraes CL. [Operationalization of cross-cultural adaptation of measurement instruments in epidemiology]. Rev Saúde Pública. 2007;41(4):665-73. Portuguese.

13. Amaral AC, Cordás TA, Conti MA, Ferreira ME. Semantic equivalence and internal consistency of the brazilian portuguese version of the Social Attitudes Towards Appearance Questionnaire-3 (SATAQ-3). Bull World Health Organ. 2011;27(8):1487-97.

14. Teixeira PC, Hearst N, Matsudo SM, Cordás TA, Conti MA. [Cross-cultural adaptation: translation and validation of the Brazilian version of Content Commitment Exercise Scale]. Rev Psiq Clín. 2011;38(1):24-8. Portuguese.

15. Bandeira M, Silva M A. Satisfaction [Scale for Patients with Mental Health Services ( SATIS - BR ): validation study]. J Bras Psiquiatr.2012; 61(3):124-32. Portuguese.

16. Melo RC, Silva MJ, Parreira PM, Ferreira MM. [Helping relationship skills in nurses: the validation of a measurement instrument]. Rev Esc Enferm USP. 2011; 45(6):1387-95. Portuguese.

17. Paschoalin HC, Griep RH, Lisboa MT, Mello DC. [Transcultural adaptation and validation of the Stanford Presenteeism Scale for the evaluation of presenteeism for Brazilian Portuguese]. Rev Latinoam Enferm.2013;21(1):388-95. Portuguese.

18. Salmerón RJ, Iglésias-Ferreira P, García DP, Mateus-Santos H, MartínezMartínez F. [Cross-cultural adaptation to the European Portuguese of the questionnaire "Patient Knowledge about their Medications" (CPMES-ES)]. Ciênc Saúde Pública. 2013;18(12): 3633-44. Portuguese. 